\title{
XLVIII. A sketch of the progress of science respecting igneous meteors and meteorites during the year 1823; including an account of the principal phœnomena of that nature observed during the same period: with inquiries suggested by those subjects
}

\section{E.W. Brayley junior A.L.S.}

To cite this article: E.W. Brayley junior A.L.S. (1824) XLVIII. A sketch of the progress of science respecting igneous meteors and meteorites during the year 1823; including an account of the principal phœnomena of that nature observed during the same period: with inquiries suggested by those subjects , Philosophical Magazine Series 1, 64:318, 287-295, DOI: $10.1080 / 14786442408644602$

To link to this article: http://dx.doi.org/10.1080/14786442408644602

Published online: 27 Jul 2009.

Submit your article to this journal $\sqsubset$

山 Article views: 2 
benefited, and the security of all classes of shipping very materially promoted thereby,-I have it in command to acquaint you, that it has been resolved to present you with the sum of two hundred pounds, as a mark of the high sense the Elder Brethren entertain of the merits and practical utility of so important a discovery.

To Peter Barlow, Esq.

I am, sir, \&c.

J. Herbert, Secretary.

XLVIII. A Sketch of the Progress of Science respecting Igneous Meteors and Meteorites during the Year 1823; including an Account of the principal Phanomena of that Nature observed during the same Period : with Inquiries suggested by those Subjects. By E.W. Brayley, junior, A.L.S., and Member of the Meteorological Society.

[Continued from p. 119.]

TNO return, however, to the phænomena of the American meteor itself:-Professor Dean, after determining the angular values of the observations made upon it by Capt. Wardner and Col. Page proceeded to calculate from them, according to the rule given by Dr. Bowditch, its actual situations when they were made, and thence the direction of its motion; with its altitude, absolute diameter, and velocity. The direction of its path, as already stated, he found to have been south $34^{\circ}$ west: at its first brilliant coruscation, as observed by Capt. W., it was about forty-one miles above the earth, or according to Col. Page, only thirty-four ; over the unsettled part of Essex county, New-York, about fifteen miles west of Crown-point; lat. $43^{\circ} 54^{\prime}$, long. $73^{\circ} 47^{\prime}$ : at its disappearance from the former gentleman, behind the ridge of a house, its elevation appeared to have been about twenty-nine miles; over the western part of Schoharie county, in lat. $42^{\circ} 45^{\prime}$, long. $74^{\circ} 49^{\prime}$. "But altitudes estimated under the impression which such a phænomenon cannot fail to produce," Prof. Dean justly observes, "must be considered as very uncertain, whatever may be the judgement and fidelity of the observers." He then states the length of the meteor's path, as probably determined from these observations; which has likewise been given in a former page of this memoir.

"I hardly dare," he continues, " to make any estimate of its velocity. I have heard no estimate of the duration of the appearance of the body of the meteor greater than five seconds; and this would imply a velocity much greater than that of the Earth in its orbit." At Salem, in Washington county, NewYork, however, where the observers do not appear to have witnessed 


\section{Progress of Science respecting Igneous Meteors in 1823.}

witnessed the explosion, and by whom, consequently, the body only of the meteor is spoken of, it is stated to have been visible for about one minute; so that the time of its passage may probably have been under-rated in the estimates alluded to by Prof. D.: although, on the other hand, common observers of such phænomena usually attribute a greater length of time to their duration than they really occupy; and several other Fire-balls on record appear to have been impelled through the atmosphere with a velocity nearly equal to that assigned to this one by Professor Dean.

Professor Dean gives two measures of the apparent diameter of this meteor, both obtained by comparison, at the time of its passage, with stationary objects; and which differed from each other only two degrees ; Capt. Wardner's object of comparison indicating it to have subtended $10^{\circ}$, and Col. Page's $12^{\circ}$. Its absolute diameter, computed from these, and from the mean distances of the observers respectively, "amounts," he states, "to about one-third of a mile." Considering the immense magnitudes which former meteors have been shown to possess ; - that Montanari calculated the smaller diameter of that which passed over Italy in 1676 to have been above halfa-mile ; that Halley computed the diameter of the fire-ball of 1719 at a mile and a half; and that Cavallo and Blagden determined that of the celebrated meteor of 1783 to have been between half and three-fifths of a mile; - the size thus ascribed to the American meteor does not appear to be excessive.

But various phænomena displayed by this meteor, indicate, I think, that we are to consider the one-third of a mile to have been merely the approximate diameter of the mass of flame, in which the solid matter or substance of the meteor was enveloped; so that the latter may have been, (and no doubt it was,) of much smaller dimensions. Thus Mr. Doty states, that "the blazing meteor was in full view over his head, appearing to be twenty or thirty feet in diameter, and soon began to extend itself to the north-east and south-west, increasing in extension, and decreasing in its flaming appearance, until nothing was to be seen but two detached parts of it rapidly moving in different directions towards the north-east and south-west." Col. Page affirms, as before stated, that when it was " about one-third of the way from Procyon to Sirius it suddenly broke out in great splendour, and continued its course flashing and sparkling east of Sirius," until it disappeared. And as neither the different distances of these and other observers from the meteor, nor the allowances necessary to be made in drawing inferences from common estimates of the àpparent diameter of such bodies, are sufficient to reconcile the great discrepancies 
in their statements on this subject; those discrepancies must have arisen, I conceive, from the circumstance, that the disk of the meteor actually varied in size at different periods of its course; and variation to such an extent as is indicated by them, in so small a space of time as that occupied by the passage of this fire-ball, could only have taken place in ignited gaseous matter, or flame, proceeding, however, from the combustion of solid matter.

Such are the grounds on which I have founded the opinion above given of the nature of this meteor; and as the assumption that the magnitude of fire-balls as computed from their distance and apparent diameter, is the actual size of the solid mass they contain, appears to have led to various misconceptions regarding them, I shall take this opportunity of submitting, with much deference, a few facts, tending to show that the magnitude of fire-balls so computed, is in no case that of the substance of the meteors; but merely of the flames with which they are invested. I am not prepared to assert that this distinction has been overlooked by every writer on the subject; but it is within my knowledge that it has been neglected by many ; and that others, who seem to have had some idea of its existence, have nevertheless derived much less use from it, in their inquiries concerning the origin and theory of such phænomena, than it appears to be capable of affording.

Thus Dr. Bowditch, in his excellent account of the meteor that exploded over Weston, in Connecticut, on the 14th of December 1807, after stating that "the least of all the limits of the diameter of the meteor is 491 feet;" proceeds to compare, in the following manner, the quantity of matter which that dimension would indicate it to have contained, with the actual weight of the stones that fell from it: "A body of this magnitude," he says, "and of the same specific gravity as the stone that fell at Weston (which weighed about 225 pounds to a cubic foot) would contain a quantity of matter exceeding in weight six millions of tons. If the specific gravity were the same as that of the air at the surface of the Earth, the quantity of matter would exceed two thousand tons: and if the specific gravity were the same as that of the air at the height of the meteor (which by the usual rule for barometrical admeasurements is about $\frac{1}{30}$ th part of that at the surface of the Earth), the quantity of matter would exceed ffty tons. Either of these estimates exceeds by far the weight of the whole mass that fell near $W$ eston, which, by the accounts published, does not appear to have been greater than half-a-ton, and would not form a sphere of two feet diameter of the same specific gravity as the stone, as was observed by Professor Day, in his valuable Vol. 64. No. 318. Oct. 1824 . $\mathrm{O}$ o paper 
paper on the origin of meteoric stones. A sphere of this diameter, seen at the distance of the meteor from Wenham, would hardly be visible without the assistance of a telescope, since its apparent diameter would not exceed two-thirds of a second. These reasons seem strongly to favour the opinion, that by far the greater part of the mass continued on its course without falling to the Earth, and the gradual disappearance of the meteor, as observed by Judge Wheeler, is agreeable to this hypothesis*."-But how different an aspect will these circumstances assume, and how different will be their bearing on theoretical inquiries, if it can be shown that we must consider the visible meteor to have been principally a mass of flame, proceeding from a solid nucleus comparatively small? I do not intend, in this place, to enter into the subject of the theory of these meteors; but shall merely endeavour to prove that it cannot be investigated, without the application of a correction for the probable difference between their size, as computed from their apparent diameter, and that of the mass of solid matter which they may respectively contain.

The chief phænomena of Bolides from which I am disposed to infer that they consist, essentially, of a nucleus of combustible solid matter, from which arises a body of flame of vastly superior magnitude, are the following: First, the characteristic appearances of inflammation which some of these meteors are said to have presented ; particularly those, which, by descending comparatively low in the atmosphere, have approached the nearest to the spectators: secondly, the frequently ovate figure of their disk, indicating their spheroidal form, with the longest axis in the direction of their motion: thirdly, the change of form which many have been seen to undergo during their progress throngh the heavens; a change, which in various instances cannot have been merely an optical deception, produced by the different aspects under which the meteors were successively viewed : fourthly, the tails which by far the greater number of fire-balls have been seen to draw after them, and from which, by some observers among the ancients, and by the uninformed in modern times, they have been occasionally confounded with comets : and fifthly, the luminous traces, often in a continuous band, or track, as it has been termed, and sometimes remaining for many minutes after the meteors' disappearance, by which their path in the heavens has in a variety of cases been marked; and which, in conjunction with their caudate appenrance, have caused many observers to compare them to immense sky-rockets.-I pro-

* Nicholson's Philosophical Journal, vol, xxwiii. p. 218: from the Memoirs of the Anerican Acadeniy. 
ceed to adduce a few of the more striking cases in which some of these phænomena have been displayed; selected from an extensive collection of similar materials now before me.

The appearances of inflammation that have been ascribed to various fire-balls, being phænomena respecting which there may exist some doubt, as they may possibly arise from deceptions of some kind, it would be unphilosophical to place any reliance upon, in support of the opinion $I$ have advanced; and yet the following instances, among others, seem to have been observed with sufficient accuracy to warrant my bringing them forward as at least collateral evidence.-The meteor seen in Italy, on the 25th of March 1719, is described by Balbus as having been "Globusigneus", a Ball of Fire ; and "apparebant in eo," he states, "hiatus, seu voragines quatuor fumum exhalantes; flammulce etiam ardentes quamplurima, quarum alice in ipso globo insidebant, alice for as emittebantur*". "The meteor which threw down the celebrated shower of stones in the vicinity of Siena in 1794, as described by Soldani, but at too great length to quote on the present occasion, had the strongest appearance of being a flaming body; the vapour which issued from it giving it the character of a cloud; as was likewise the case with that which produced the tremendous shower at L'Aigle in 1803. A brisk scintillation, like that of a fire-brand carried against the wind, was observed about the body of the meteor from which descended the shower of stones at Weston, in Connecticut, in 1807.-When the fireball beheld in London, on the 13th of November 1803, increased in brilliancy, and became ovate in form, about a second or a second and a half before its disappearance, " it seemed," Mr. Firminger states, "as if the meteor had before been covered with one external coat, which now burst or separated in the middle the whole length of its. longest diameter, and exposed a surface with a brightness far surpassing its former lustret." This appearance, also, I conceive, could only have been produced by an inflamed body undergoing intense combustion.

The instances of Bolides having a spheroidal form, with the longest diameter in the direction of their motion, are too numerous, and too well known, to need recital here; and the inference to be drawn from them, with regard to the nature of the meteors is too obvious to require pointing out.

Evident proofs of actual and considerable variation, in form as well as in size, are afforded, I think, by nearly all the detailed accounts of large Fire-balls that have been published:

* Commentarii Bononienses; tom. i. c. $285 . \quad+$ Phil. Mag. vol. xvii. p. 279. $0 \circ 2$ 
by Sir John Pringle's collection of observations on that which appeared in 1758, for example; by Dr. Blagden's memoir written on occasion of that of 1783 ; and likewise by the observations on the American meteor of 1822, of which I have already given a summary.

The elongation of the flames enveloping the nucleus of meteors, from the resistance of the atmosphere to their immense velocity, seems to produce the caudate appearance, always in the direction opposite to that of their motion by which the majority of them are characterized; and from which also they have been described as conical and pear-shaped, and compared in figure to trumpets, \&c.; cases of this sort it would be superfluous to adduce, as every memoir upon the subject is replete with them.

The same may be said of the luminous tracks which are so frequently left in the atmosphere by meteors of this description; and several instances of them have already been noticed in this paper. They appear scarcely explicable but on the supposition that they consist of ignited solid matter in a state of minute division, and resulting from the combustion going on in the meteors whose aërial course they distinguish.

I have stated, at the outset, my reasons for bringing forward the foregoing brief statement and cursory illustrations of the opinion respecting the nature of Bolides, which the comparison of a variety of accounts of them has induced me to form: the subject involves many others, and some of great interest: such, for instance, as the determination of the species of combustion going on in these meteors; the data for which are the phænomena with regard to the evolution of light and heat of the fire-balls themselves, the nature of the substances cast down by their explosions, and the results of Sir H. Davy's ' Researches on Flame.'

The examination of these subjects, however, I must reserve for another place; and with merely an allusion to the bearing of the question on which I have endeavoured to support an opinion, upon the comparison of the computed magnitude of any one meteor with that of another (see p. 116.), and also on the great variation in apparent diameter of the same meteor as seen by different observers (ibid.), I will conclude this digression; and proceed with the historical review of the progress of science respecting igneous meteors during the past year.

M. Moreau de Jonnès, to whom science is indebted for much information respecting the climate, physical geography, and natural history of the West Indian lslands, communicated to the Royal Academy of Sciences of Paris, on the 30th of December 1822, an extract of a letter from Fort Royal, in Mar- 
tinique; relating the passage of a meteor over the island, at eight in the evening of the 1st of September in that year. When this took place, the sky was covered with clouds in rapid motion : the meteor was of considerable magnitude, and having been seen advancing over the Caribbean sea for several minutes, proceeded with extraordinary velocity from west to east, towards the coast of the island. It is stated to have produced, during its passage, a noise resembling the rolling of thunder; and to bave exploded, at the instant which preceded its disappearance, with an extremely violent detonation. The terror it caused among the inhabitants was so great, that some of them swooned away, and others were seized with illness*. M. Moreau de Jonnès observes, at the conclusion of the notice, "It is to be wished that this phænomenon had been observed at other places, in a more precise manner : it must however be remarked, that, supposing it to have been the fall of an aèrolite, of which we have yet no instance in the American islands, there is but little hope of obtaining decisive evidence to that effect, in an island deeply penetrated by inlets of the sea, and more than half covered with forestst."

I may here remark, that a paper in vol. $\mathrm{xxx}$ of the Philosophical Transactions, by Mr. Henry Barham, F.R.S., affords distinct evidence of the fall of a shower of meteorites near St. Jago de la Vega, in Jamaica, about the year 1700; although the writer was not aware of the fact; the observers not having had the curiosity to dig up the stones, though they endeavoured to probe the deep holes in the ground which had been produced by their fall.

Mr. Davenport has published a notice of a Fire-ball seen by him, whilst travelling northward on the Hastings road, on the 28th of October 1822. He was slowly ascending Silver Hill, which is about forty-eight miles south-east of London, by road measurement, at about half-past five in the afternoon: the sky being clear, the moon nearly full, and shining bright, the sun below the horizon, but the twilight still strong; when he beheld the meteor in the north-east, and at the altitude of about $22^{\circ}$, by estimation. It was fully equal to one-third of the apparent diameter of the moon when at full; and gave a remarkably bright and white light. It passed towards the west in a horizontal direction, the length of its path while it continued visible being above $20^{\circ}$, which it occupied about eight seconds in traversing. It disappeared from Mr. D. by passing

- May we infer from these circumstances that the meteor was very near the island at the time of its explosion; so that the report and concussion of the atmosphere were experienced in an intense degree by the parties thus affected?

† Revue Encyclopédique, vol. xvii. p. 191. 


\section{Progress of Science respecting Igneous Meteors in 1823.}

behind a loaded waggon. He published his observations with the view of their being compared with those of other persons who might have seen the phænomenon; but no further account of it has appeared*.

I shall close this part of the subject with a fact of my own observation. On the night of the 10th of December 1822, whilst walking near the top of Groswell Road, Islington, I beheld, at about half-past eleven, a very beautiful caudate meteor, its general shape much resembling that of a trumpet; to which the smaller fire-balls of this kind have been frequently compared. The head, which had a sort of burr around it, appeared to be of about one-third of the diameter of the fullmoon, and was of a very brilliant white colour, with a tinge of blue: the tail, which was very long, was also white at the upper end, but of a full red colour for the lower and greater portion of its length ; a circumstance, likewise, which has often been noticed in meteors of this description. The meteor darted down from near the zenith in a north-westerly direction, for about $30^{\circ}$, the wider part seeming to become attenuated into the tail, which disappeared in a few seconds without leaving any track or other traces in the sky, then clear and star-light. A similar phænomenon, I was subsequently informed, had been witnessed on the night of Nov. 5 ; and another on that of Dec. 7.

Dr. T. Forster, F.L.S. and Member of the Meteorological Society, has published a third edition, corrected and enlarged, of his "Researches about Atmospheric Phenomena;" but the chapter on Igneous Meteors and Meteorites, and the observations on those subjects in that on Electricity, remain as they were in the second edition, published in 1815: the Calendar of Nature, however, which the author has now appended to his work, records some observations on Shooting Stars. He remarks that those meteors are very prevalent about August; particularly with east winds.

In No. III. of Gilbert's Annalen der Physik, for 1823, is an announcement by Professor Brandes, of Breslau, of the hours at which observations would be made on the same interesting phænomena, at Quedlinbourg, Halle, Liegnitz, and Breslau, during the year: I am not aware that the observations have been published. Prof. B. has furnished meteorologists, at various times, with many useful observations on the altitude, velocity, and magnitude of shooting-stars.

Signor Angelo Bellani, of Pavia, a philosopher who has become advantageously known to meteorologists by his announcement and subsequent investigation of the depression

* Annals of Philosophy, N. S. vol. v.

which 
which in time takes place in the freezing point of thermometers, has published a memoir on Shooting Stars, in which he supports the theory, that those meteors are caused by the combustion of trains of inflammable gases or vapours in the atmosphere. He thinks that such trains may exist in the higher regions without being dissipated, in consequence of the general and perfect tranquillity which may be considered as reigning there: and he endeavours to combat the difficulty generally urged against this theory, - the diminished inflammability by expansion of gaseous or vaporous mixtures,-by referring to the vapour of phosphorus; stating, "that phosphorus becomes luminous, or suffers a slow combustion, at a temperature so much the lower as the quantity of oxygen gas in a determinate space is rendered smaller, either by mixture with other gases, or by rarefaction." He then ventures the conjecture, that there may be other substances, capable by natural operations of being reduced to the state of vapour or gas, and which, though not inflammable at common temperature and pressure, may become so by being elevated in the atmosphere*.

[To be continued.]

XLIX. Reply to Mr. Samuel Cooper's Queries un finding the exact Mean Solar Time.

To the Editors of the Philosophical Magazine and Journal. Gentlemen,

I $N$ the last number of your Magazine, pages 210 and 211 , 1 there is a curious solution of Mr. Samuel Cooper's for finding Mean Solar Time by an altitude of the sun, taken with a reflecting circle and an artificial horizon: also some queries as to the accuracy of his method, \&c. I beg to observe that although it appears to me to be rather an awkward and far-fetched form, involving unnecessary trouble, yet with the reduced latitude, as Mr. C. terms it, the sun's reduced declination, and his true altitude, he has succeeded in bringing out the mean time within $1^{s \cdot 6}$ of what it is by the first method given in the third edition of Mackay's work on the Lcngitude, \&c. page 126 ; or by the second method in Norie's Navigation. He will find either of these methods shorter and more expeditious for finding apparent time, at the same time they are better known by mathematicians. Mr. Cooper's plirases, "apparent and visible latitude, and visible altitude" are not scientifically expressed; therefore they ought to be avoided, to prevent any ambiguity in the expressions of their sexagesimal quantities: From the substance of the question I make the latitude of

* Journal of Science, \&c, vol. xv. p. 391.

Pertenhall, 